\title{
Towards an effective electronic waste management scheme in Attica, Greece
}

\author{
M. Menegaki \& D. Kaliampakos \\ School of Mining and Metallurgical Engineering, \\ National Technical University of Athens, Greece
}

\begin{abstract}
Electronic wastes (e-wastes) pose a significant threat to human health and the ecosystem, due to both the volume of wastes produced and the hazardous materials contained. Discarded electronic equipment is one of the fastest growing waste streams worldwide, due to the increasing growth rate of the Information Technology (IT) market and the rapid obsolescence of the equipment.

The European Union has characterized the Waste from Electrical and Electronic Equipment (WEEE), in general, as one of the key waste streams and has already developed the framework for their management.

Although a lot of EU countries have already launched their electronic wastes policy, Greece started the efforts quite recently. Granted that the Greek IT market is expected to grow significantly in the near future, it is obvious that the need for immediate action is more urgent than ever, so as to be able to deal with the problems that will occur due to the accumulation of significant quantities of e-wastes.
\end{abstract}

The paper presents the process so far of a project, funded by European Regional Development Fund, which aims to develop an integrated management system for electronic wastes in the Attica Region.

Keywords: electronic waste management.

\section{Introduction}

The Waste from Electric and Electronic Equipment (WEEE) constitutes one of the most rapidly developing waste streams. The WEEE annual production in EU is estimated at 6 million tons, while the WEEE annual growth rate is about 3 to 
$5 \%$. The significantly increasing rate is mainly the result of the rapid expansion of the industry of personal computers (PCs).

The manufacture of a personal computer demands the complex assembly of hundreds of materials. At the same time, an innovative product becomes obsolete in a short time period. Nowadays, the average life of PCs ranges between 2 and 5 years and is expected to become shorter in the near future, due to the continuously increasing needs of the end users.

European Union has characterized the WEEE, in general, as one of the key waste streams and has already developed the framework for their management (EU Directives: 2002/96/EC; 2002/95/EC; 2003/108/EC). EU legislation requires each Member State to draw up one or more waste management plans in accordance with relevant EU directives. As a result, a lot of the EU countries have already developed a plan for the management of electronic wastes.

In Greece, the need to design an electronic waste management plan became visible a few years ago, when there was an explosive entry of PCs in the marketplace. More specifically, the size of the Greek market of PCs and servers has been tripled from 1995 to 2000 .

This situation has led, gradually, to the accumulation of large quantities of electronic wastes, which, in the most of the cases, are disposed of together with municipal wastes. The problem is expected to be more intense in the near future, due to the increasing quantities of wastes that will be produced, as a result of the continuing growth of the Greek information technology market.

On the ground of the above, a systematic effort has started, so as to draw the lines of a successful management scheme, focused on the Attica Region, since a large part of the Greek population (approximately 34\%) is concentrated there and at the same time, Attica presents the biggest percentage of PC users among all other Greek Regions. Moreover the majority of the Greek IT market (approximately 68\%) is located in the wider area of Attica.

This effort constitutes one of the main actions of the regional program "Information Society for the quality of life in the Region of Attica", funded by the European Regional Development Fund (ERDF).

The paper presents the methodological approach as well as the main results achieved until now.

\section{Overview of the problem}

Computer waste is a serious environmental concern, primarily because of its toxicity. According to studies, electronics account for only 1 percent of the content of landfills by volume, but they contribute up to 70 percent of their toxic content $[1,2]$. More specifically:

- $\quad$ The cathode ray tubes (CRTs) in most computer monitors have x-ray shields that contain significant quantity of lead, mostly embedded in glass. Discarded monitors together with televisions are believed to be the largest sources of lead in landfills [3]. 
- A PC's central processing unit (CPU) typically contains toxic heavy metals such as mercury (in switches), lead (in circuit boards), and cadmium (in batteries).

- Plastics used to house computer equipment and cover wire cables often contain polybrominated flame-retardants, a class of chemicals similar to PCBs.

Lead, mercury, cadmium and polybrominated flame-retardants are all persistent, bioaccumulative toxins (PBTs) that can contaminate groundwater and pose other environmental and health risks when computers are manufactured, incinerated or landfilled [4]. Even recycling of e-waste, if not properly treated, can cause additional environmental problems.

The quantities that are recycled remain very low, while the main volume is being landfilled, incinerated, or stored away in closets or warehouses. The latter is mainly due to the reluctance of the people to discard electronic equipment as trash. Also, in a lot of cases, consumers are unclear about how to dispose of or get rid of old computers and e-waste. At the same time, a lot of producers and retailers insist on ignoring the problem. If this situation continues for a long time, there would be a large quantity of "historical" wastes that will escalate the problem of electronic waste management.

\section{The Greek IT market}

The Greek IT sector, although lagging behind in comparison with the EU countries, is characterized by a strong rate of growth (Table 1). During the last years, the growth rate of the IT market in Greece was at least two times higher than the average growth rate of the respective market in the other EU countries (Table 2). This was the result of the development and modernization of the public and the private sector. However, it should be noted that the growth rate of the Greek market has started slowing down from the year 2000. According to analysts, this was the result of the great delay of the inflow of capitals from the $3^{\text {rd }}$ Community Support Framework. Therefore, the most pessimistic projections state that in the near future the Greek IT market will present a continuously anodic drift, which will be at least the same as in the rest EU countries.

Table 1: Growth rate of the Greek IT market (including PCs and servers) from 1995 to 2003 [5].

\begin{tabular}{|c|c|c||c|c|c|}
\hline Year & $\begin{array}{c}\text { Market size } \\
\text { (in items) }\end{array}$ & Growth rate & Year & $\begin{array}{c}\text { Market size } \\
\text { (in items) }\end{array}$ & Growth rate \\
\hline 1995 & 115.000 & - & 2000 & 402.000 & $34.0 \%$ \\
\hline 1996 & 130.000 & $13.0 \%$ & 2001 & 460.000 & $14.4 \%$ \\
\hline 1997 & 160.000 & $23.1 \%$ & 2002 & 445.000 & $-3.3 \%$ \\
\hline 1998 & 200.000 & $25.0 \%$ & $2003 *$ & 458.000 & $2.9 \%$ \\
\hline 1999 & 300.000 & $50.0 \%$ & \multicolumn{4}{|l}{} \\
\hline
\end{tabular}

*Estimation; Source: ICAP. 
Table 2: Annual consumption per capita for IT products and services in Western Europe (in euro) [5].

\begin{tabular}{|l|c|c|c|c|}
\hline Country & $\mathbf{1 9 9 9}$ & $\mathbf{2 0 0 0}$ & $\mathbf{2 0 0 1}$ & $\mathbf{2 0 0 2}$ \\
\hline Austria & 720 & 791 & 791 & 766 \\
\hline Belgium/Luxemburg & 718 & 767 & 782 & 752 \\
\hline Denmark & 1,224 & 1,281 & 1,231 & 1,197 \\
\hline Finland & 866 & 935 & 927 & 931 \\
\hline France & 789 & 819 & 847 & 842 \\
\hline Germany & 788 & 828 & 833 & 802 \\
\hline Greece & 154 & 178 & 179 & 172 \\
\hline Ireland & 621 & 667 & 633 & 606 \\
\hline Italy & 399 & 414 & 431 & 428 \\
\hline Netherlands & 1,023 & 1,055 & 1,041 & 1,032 \\
\hline Portugal & 230 & 248 & 262 & 249 \\
\hline Spain & 271 & 283 & 292 & 291 \\
\hline United Kingdom & 991 & 1,074 & 1,080 & 1,075 \\
\hline Sweden & 1,267 & 1,296 & 1,310 & 1,298 \\
\hline Switzerland & 1,573 & 1,635 & 1,621 & 1,562 \\
\hline Norway & 1,256 & 1,345 & 1,337 & 1,293 \\
\hline Source: EITO 2003 & & \multicolumn{3}{|l}{}
\end{tabular}

Source: EITO 2003.

\section{Current management practices}

\subsection{The recycling techniques}

The available recycling techniques do not differ significantly. More specifically, the treatment procedure is either fully or partial automated and includes the following stages: dismantling, depollution, shredding and sorting of materials. After dismantling, the parts that can be reused for upgrading of old computers are forwarded to the refurbishment process. During the depollution stage, the dangerous components (switches, batteries, etc.) are removed. These components are treated at accredited processing plants.

The shredding equipment used is depending, mainly, on the required recovery rate. The crushed materials can be sorted using various separation techniques. The main products from the recycling process are ferrous metals, non-ferrous metals and plastics. The non-ferrous metals are transported to special fusion furnaces. The metals leave these furnaces in such a pure state that can be reused as raw materials for making cables and new electronic components. The recovered ferrous metals are used in the steel industry. The recovered plastics can be reused, after special treatment, in the car and furniture industries. However, because of their low quality, the recovered plastics are usually used as fuels in kilns, while the secondary plastics are incinerated.

An extensive research is currently carried out for the treatment of the CRT monitors. Following dismantling, the picture tubes can be processed according to two methods. In the first, the glass is crushed and then washed, so as to remove 
the fluorescent powder. In the second, the screen is split into two parts (front and rear glass) and the phosphorescent powder is sucked off. Then, the two parts of glass are crushed separately, since they contain different hazardous substances. The cleaned glass is used, mainly, in the manufacture of new picture tubes or in ceramics industry.

Special treatment is implemented, in several cases, for the Printed Circuit Boards (PCBs), which are led directly to smelters for precious metals recovery.

\subsection{The management schemes in Europe}

Europe presents the most integrated management schemes worldwide, although there are significant differences between them. The factors that affect the scheme operation include geography, population size/density, labour cost, product scope, industry participation and organisation, legal requirements and standards, and scheme maturity. Scheme performance is, also, largely dependent upon the prevailing national recycling culture and public willingness to engage.

The majority of schemes run by Producer Responsibility Organisations (PROs). The exception is Denmark, where municipal and regional authority collectives currently operate the WEEE schemes [6]. Many management schemes handle electronic together with electrical waste (e.g. El Kretsen in Sweden). However, there are some management schemes that work only on electronic waste (e.g. ICT Milieu in Netherlands).

The rate of separate collection of at least four kilograms of WEEE per inhabitant per year, imposed by the EU directive, has already been achieved in most of the European countries. Further, many countries try to increase the above rate as much as possible.

The collection of the waste is the most difficult part that a management scheme has to face. The problem is more intense in the CRT monitors, which are too heavy and fragile. There are three primary channels for collection of e-waste: municipal collection sites, in store retailer take-back, and producer take-back. The majority of schemes have adapted the municipal collection system. Some schemes, such as ICT Milieu in Netherlands, use this channel exclusively. Others, such as Recupel in Belgium and El-Retur in Norway, encourage retailer participation, but this does not exceed the $30 \%$ of total volume collected. All schemes outsource the majority of their transport and treatment activities to commercial suppliers, usually on the basis of 2-3 year competitively tendered contracts.

The level of administrative complexity reflects the way they raise revenues, as well as the financial and operational role that they play. In general, the financial structure is based upon a fee. This fee can be charged directly to the producer, according to the number and category of equipment sold in a certain period. This cost is passed onto the consumer at the time of purchase of a new product. Although EU directives mention that this extra cost should not be shown to the purchasers, some schemes have established a visible fee (e.g. Recupel). However, the majority of schemes prefer to charge the participants in the system according to their market share. 
The free riders, which currently represent the 10 to $20 \%$ of the volume of products placed on the market, remain a problem for all the schemes. The total cost for the management of wastes in the various European management schemes ranges between 0.45 and $0.80 € / \mathrm{kg}$. The biggest proportion of this amount concerns the collection and transportation cost.

There is a wide variation in the level of expenditures for communication and marketing activities between schemes, and as a consequence, in the level of consumer awareness. Visible fee schemes, such as NVMP and Recupel invest up to $4 \%$ of budget in public relation activities, including television, print media and point of sale (POS) materials. They also conduct consumer research, indicating that they have achieved levels of consumer awareness of approximately $70 \%$.

\section{Building an efficient e-waste management system}

Taking into account that there has been a total lack of management consideration in regard to e-waste, in Greece, the management system should be designed from scratch. The development of the methodology is crucial for the drawing of the policy that should be followed so as to end to a successful electronic waste management scheme. There are a lot of critical questions that have to be answered, with the most important being:

- The volume and the annual rate of e-waste entering into the system.

- The proportion of free-rider/orphan products entering into the system.

- The collectable volume of historical waste.

- The way that the producers will be charged for their waste.

- The distribution of management cost for the historical waste and the orphan products.

- The role of municipalities in the collection process.

- The motives to the users so as to ensure their participation in the collection process.

- The degree of the system automation (manual or automation dismantling, separation and recovery rate, etc.).

- The training of the personnel.

- The possible engagement of sensitive social groups (e.g. disabled).

- The potential subcontracting for transportation and recycling.

- The way of re-marketing systems and components that can be reused.

- The capability of the market to absorb the recycling products or exporting some of them.

- The way of disposal of non-recyclable components and residues from the recycling process.

The answer to the above questions will finally lead to the realization of an integrated business and action plan, which will ensure the technical feasibility and the economic viability of such an investment.

The main steps of the methodology are given in Figure 1. 


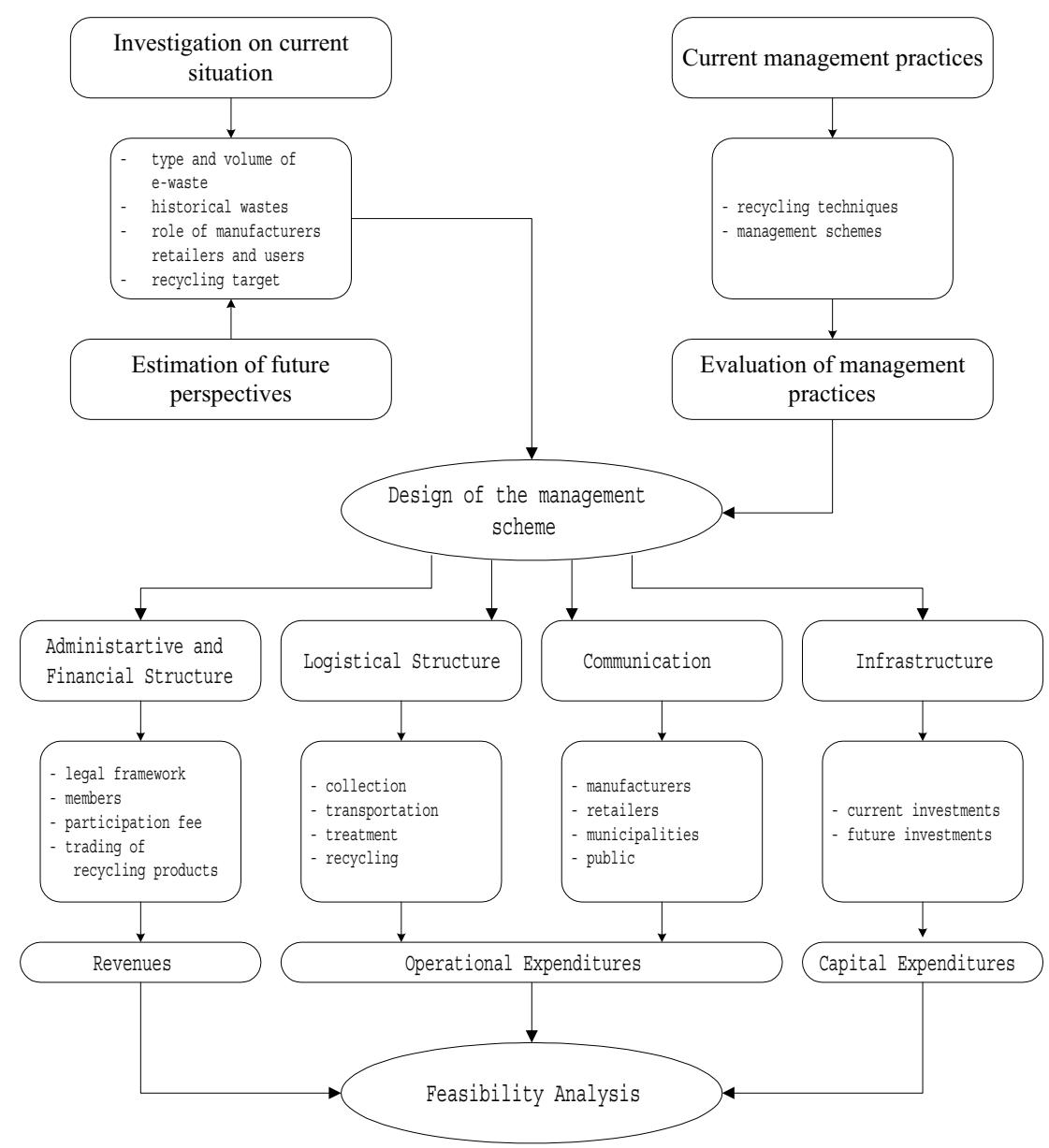

Figure 1: $\quad$ Main steps of the methodology.

Up to now, the investigations on the e-waste management policies and techniques that are in use worldwide, as well as the examination of the current situation in Greece, have been completed.

\section{Results - discussion}

According to the experience of other European countries, the electronic wastes generated annually, do no exceed the $12.5 \%$ of the total WEEE. Based on the estimations that have been made from researchers [7], in regard to the annual WEEE amounts in the Region of Attica for the years 2003 to 2007, the respective amount of e-wastes was calculated as shown in Table 3. 
Table 3: Annual e-wastes amounts (in tons) for the years 2003-2007 in the Attica Region.

\begin{tabular}{|c|c|c|c|c|c|}
\hline & $\mathbf{2 0 0 3}$ & $\mathbf{2 0 0 4}$ & $\mathbf{2 0 0 5}$ & $\mathbf{2 0 0 6}$ & $\mathbf{2 0 0 7}$ \\
\hline WEEE & 59,344 & 59,718 & 60,094 & 60,472 & 60,853 \\
\hline e-wastes (12.5\% of the WEEE) & 7,418 & 7,465 & 7,512 & 7,559 & 7,607 \\
\hline
\end{tabular}

The investigation of the current situation was based on data, which were collected by means of telephone and face-to-face surveys on PC users, manufacturers and retailers. From the data collected until now the following results are obtained:

- There is a significant percentage among the respondents, which ignores the existence of hazardous substances into the PCs.

- The majority of the domestic users do not throw away their old PC. Some of them prefer to store it, while others sell it or gift it, which practically means that a part of the old equipment is currently reused. Moreover, there are a lot of commercial users that store the obsolete equipment in warehouses. As a result, there are already significant quantities of historical wastes to deal with straightforward. Otherwise significant quantities of e-waste will end up to landfills.

- The public, although not well informed, seems to understand the necessity of the development of an e-waste management system.

- The most convenient take back system seems to be the collection from the house in regard to the domestic users. For that reason, the municipalities should play a major role in the system.

- The manufacturers and retailers are not willing, at least for the time being, to get involved in the management system. Therefore, a way to enforce them to take responsibility immediately should be found. It is obvious, that their participation will accelerate the whole processes.

- The manufacturers and retailers estimated that the market could not afford an extra fee more than 5 euro in the purchase value of a new PC. On the other hand, and this is most important, the domestic and commercial users seem to be willing to pay an average fee of about 31 euro and 20 euro respectively.

- As for the recycling products, plastics are the most difficult to deal with, due to the lack of incineration technologies in Greece. A possible solution for the second category plastics is their utilization as fuels in kilns of metallurgy or cement production.

\section{References}

[1] McDonnell, E., Turning Wastestream Materials into Economic Opportunities, Demanufacturing Partnership Program Newsletter, New Jersey Institute of Technology, 1997.

[2] U. S. Environmental Protection Agency. Computers, E-Waste, and Product Stewardship: Is California Ready for the Challenge?, Global Futures Foundation, 2001. 
[3] USA Sitting on Mountain of Obsolete PCs, USA Today, 22 June 1999.

[4] Pare, M., Metech Seizes Opportunity in Computer Salvage, High Tech, 30 November 1998.

[5] ICAP. Study on the Greek IT sector, Athens, 2004.

[6] U. S. Environmental Protection Agency. Computers, E-Waste, and Product Stewardship: Is California Ready for the Challenge?, Global Futures Foundation, 2001.

[7] Ecological Recycling Society. Economic impact study on the sustainable management of e-waste in Greece, LIFE ENV/GR/000688, Athens, 2003. 